Revista Tecné, Episteme y Didaxis: TED. Año 2014, Número Extraordinario. ISSN Impreso: 0121-3814, ISSN web: 2323-0126

Memorias, Sexto Congreso Internacional sobre Formación de Profesores de Ciencias. 08 al 10 de octubre de 2014, Bogotá

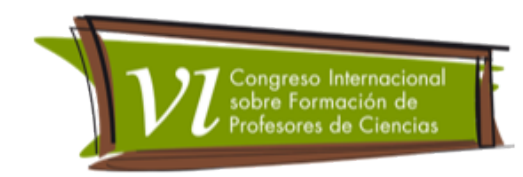

\title{
Análise do conhecimento pedagógico do conteúdo a partir da perspectiva do educando
}

\author{
Girotto Jr. Gildo,' Fernandez Carmen²
}

Categoria 2. Trabalho de investigação

\section{Resumo}

Partindo da proposta de estudo da base de conhecimentos para o ensino, procuramos estudar a influência da percepção dos estudantes no reconhecimento do Conhecimento Pedagógico do Conteúdo (PCK) a partir de uma análise qualitativa e quantitativa. Foram coletados dados sobre 0 planejamento e sobre as representações do conteúdo de um professor em uma disciplina de graduação, dados a partir da observação e registros audiovisuais das aulas e entrevistas com o professor e com os alunos. Baseado no referencial teórico de Shulman e no modelo de representação do PCK de Morine-Dershimer e Kent, verificamos que há componentes do PCK que são expressos com maior clareza pelos estudantes frente a outros. Ainda, a análise quantitativa, apesar de apresentar pontos incertos, aponta indícios de concordância com a análise qualitativa podendo auxiliar no reconhecimento do PCK.

\section{Palavras Chave}

Conhecimento Profissional, Conhecimento Pedagógico do conteúdo, relação professor-aluno, percepção de estudantes.

\section{Objetivo}

O trabalho tem por objetivo o reconhecimento do PCK realizando análises a partir da observação da prática profissional, buscando compreender se as percepções que os estudantes possuem podem auxiliar no reconhecimento de categorias do conhecimento profissional de professores.

\footnotetext{
1 Programa de Pós Graduação Interunidades em Ensino de Ciências da Universidade de São Paulo. Email: ggirotto@gmail.com

2 Programa de Pós Graduação Interunidades em Ensino de Ciências da Universidade de São Paulo Instituto de Química, Universidade de São Paulo. Email: carmen@iq.usp.br
} 
Revista Tecné, Episteme y Didaxis: TED. Año 2014, Número Extraordinario. ISSN Impreso: 0121-3814, ISSN web: 2323-0126

Memorias, Sexto Congreso Internacional sobre Formación de Profesores de Ciencias. 08 al 10 de octubre de 2014, Bogotá

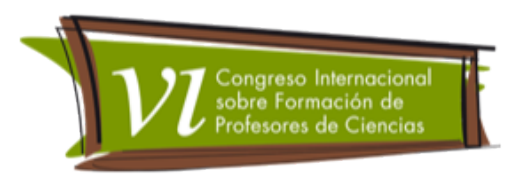

Procuramos, portanto, reconhecer as representações que os alunos evidenciam a respeito do PCK dos professores de química e relacionar os modelos de PCK construídos com a análise feita pelo pesquisador.

\section{Marco Teórico}

A pesquisa sobre o desenvolvimento do conhecimento profissional de professores vem sendo amplamente estudada considerando diferentes vieses. Compreender quais os saberes profissionais (Talanquer, 2004, Tardif, 2010), como ocorre seu desenvolvimento (Nilsson e van Driel, 2010) e as formas como acessamos estes conhecimentos fazem parte das pesquisas relatadas.

Na análise do conhecimento profissional, destacam-se as idéias de Shulman (1987), o qual propôs sete categorias de conhecimento profissional que vem sendo estudadas e reformuladas por diferentes autores com o intuito de sistematizá-las em modelos que tenham por objetivo a análise da prática profissional de professores. Neste contexto surge a ideia do Conhecimento Pedagógico do Conteúdo (PCK - sigla em inglês) o qual representa um conhecimento que os professores começam a adquirir na formação inicial e desenvolvem com o passar dos anos de experiência, sobre como ensinar determinado conteúdo particular a fim de obter a compreensão dos estudantes.

Na tentativa de compreender o PCK e reconhecer seus componentes, diversos autores buscaram acrescentar ou suplantar categorias frente à proposta inicial e ainda, criar modelos de interpretação deste conhecimento na tentativa de interligar seus componentes e propor estratégias para o seu reconhecimento. (Morine-Dershimer e Kent, 1999, Rollnick et al., 2008).

As diferentes metodologias de análise e promoção do desenvolvimento do PCK de professores envolvem o estudo e reflexão a respeito dos planejamentos, dos registros audiovisuais, do desenvolvimento do processo reflexivo sobre a prática, buscando por vezes a interpretação frente a modelos teóricos do PCK (Nilsson et al., 2010). Mais recentemente, têm surgido trabalhos relacionados ao PCK a partir da análise quantitativa (Olszewski, 2010, Jang, 2010). Ainda há trabalhos que buscam nas percepções dos estudantes, subsídios para a compreensão / interpretação do PCK de professores. Neste contexto, buscamos relacionar a análise feita pelo pesquisador com as percepções que os estudantes apontam a respeito do PCK. Pretendemos observar se há concordância entre as análises e, portanto, se as percepções dos estudantes podem auxiliar o reconhecimento dos conhecimentos profissionais. Ainda, buscamos investigar uma proposta de análise 
Revista Tecné, Episteme y Didaxis: TED. Año 2014, Número Extraordinario. ISSN Impreso: 0121-3814, ISSN web: 2323-0126

Memorias, Sexto Congreso Internacional sobre Formación de Profesores de Ciencias. 08 al 10 de octubre de 2014, Bogotá

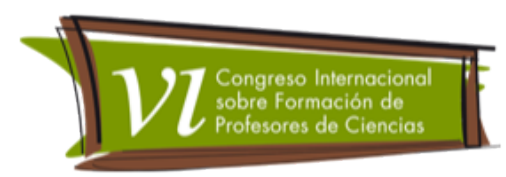

quantitativa, visando combinar na investigação aspectos qualitativos e quantitativos juntamente com a percepção dos estudantes, objetivando uma nova proposta de metodologia de investigação.

\section{Metodologia}

O presente trabalho envolveu a coleta e análise de dados de um professor e alunos de uma disciplina do curso de graduação em Ciência e Tecnologia de uma instituição localizada em São Paulo, Brasil.

Para reconhecer O PCK do professor foram coletados os seguintes dados: planejamento da disciplina e das aulas, registros audiovisuais, o instrumento CoRe - Representação de Conteúdo, (Loughran, Mulhall, Berry, 2004), e entrevista semiestruturada.

Tais dados foram analisados buscando interpretar os conhecimentos do professor em relação ao modelo de Morine-Dershimer et al. (1999) o qual denominaremos M1. A análise dos registros audiovisuais foi feita utilizando a ferramenta desenvolvida por Mortimer e Scott (2002), a qual permite analisar a convergência entre o discurso e as ações dos professores.

A coleta de dados referentes às percepções dos estudantes englobou questionários (QA) e entrevistas (EA) semiestruturadas abordando aspectos relativos às categorias relacionadas ao PCK.

O questionário (QA) utilizado baseou-se no instrumento desenvolvido por Jang (2010), contendo 28 perguntas, divididas em quatro categorias de conhecimento: Conhecimento do Tema (CT), Estratégias Instrucionais e de Representação (EIR), Objetivos Instrucionais e Contexto (OIC) e Conhecimento sobre a Compreensão dos Estudantes (CCE). Utilizou-se uma escala Likert de 5 pontos. Os dados obtidos no QA foram trabalhados estatisticamente e os resultados comparados com a análise qualitativa obtida através das entrevistas. A entrevista semiestruturada realizada apresentou o objetivo de coletar as impressões dos alunos a respeito da prática docente. Em tal entrevista foram questionados aspectos baseados nas categorias de conhecimento expostas no questionário QA de modo que as respostas obtidas puderam ser comparadas com os dados dos questionários. 
Revista Tecné, Episteme y Didaxis: TED. Año 2014, Número Extraordinario. ISSN Impreso: 0121-3814, ISSN web: 2323-0126

Memorias, Sexto Congreso Internacional sobre Formación de Profesores de Ciencias. 08 al 10 de octubre de 2014, Bogotá

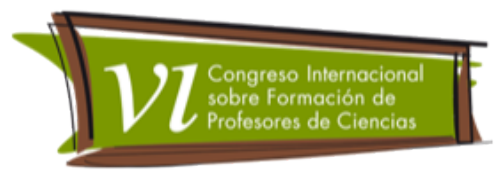

Figura 1. Modelo adaptado de Morine-Dershimer e Kent (1999): conhecimentos que contribuem para o PCK.
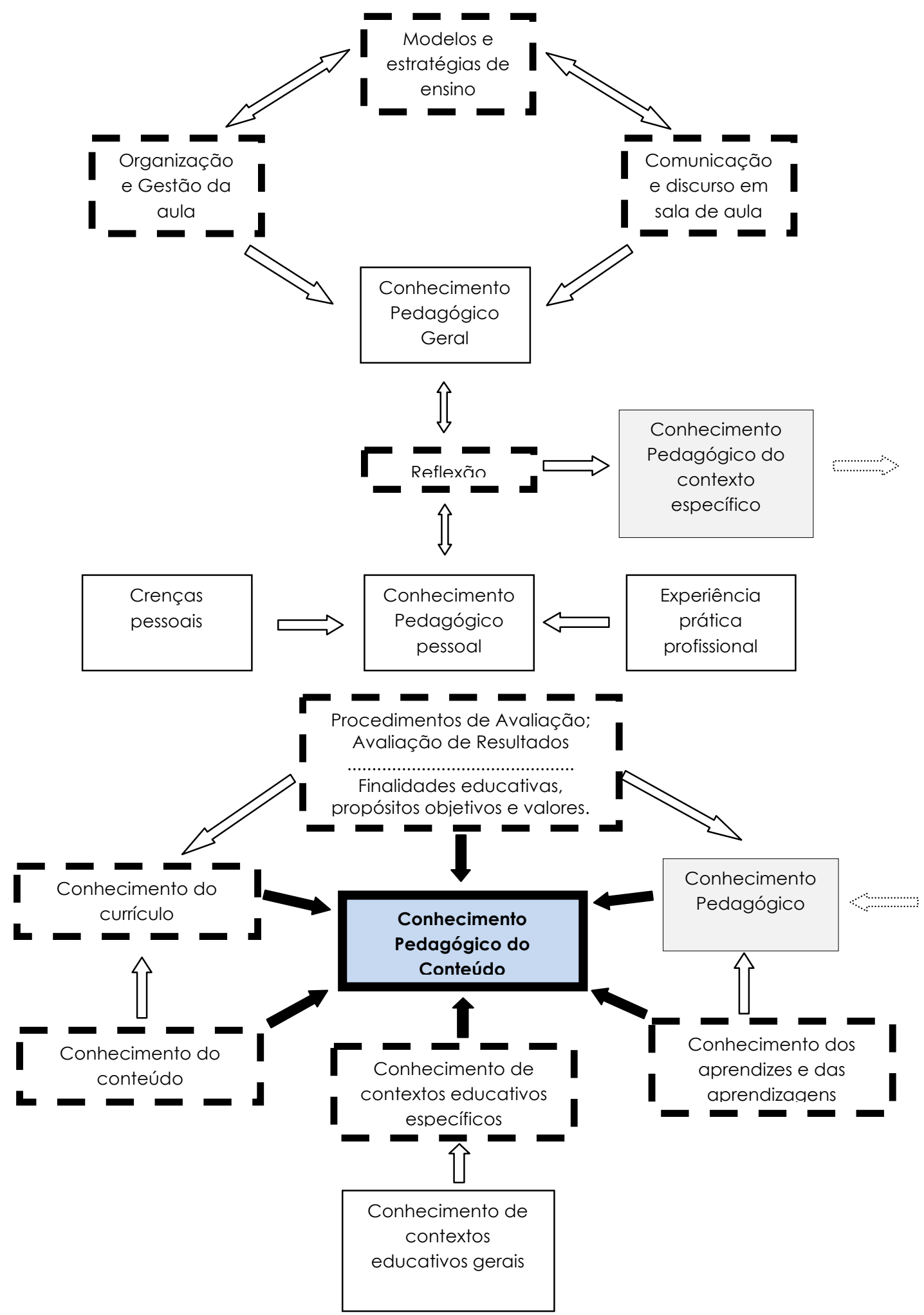
Revista Tecné, Episteme y Didaxis: TED. Año 2014, Número Extraordinario. ISSN Impreso: 0121-3814, ISSN web: 2323-0126

Memorias, Sexto Congreso Internacional sobre Formación de Profesores de Ciencias. 08 al 10 de octubre de 2014, Bogotá

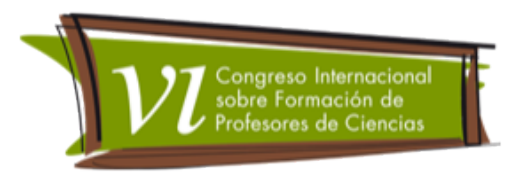

\section{Resultados}

A partir da análise dos dados foi possível destacar manifestações que demonstram que o professor possui desenvolvidas diferentes categorias de conhecimento relacionadas ao PCK.

A análise dos registros audiovisuais utilizando a ferramenta de Mortimer e Scott (2002) permitiu reconhecer padrões de interação e ações do professor que corroboravam com o proposto no planejamento e no CoRe. Tais instrumentos permitiram reconhecer categorias de conhecimentos que o professor possui. A figura 1 ilustra 0 modelo $\mathbf{M 1}$, no qual destacamos (linhas tracejadas) os conhecimentos observados para o professor. Ao analisarmos o modelo em destaque, vemos que os conhecimentos observados nesta análise estão diretamente relacionados ao Conhecimento Pedagógico Geral e ao PCK.

Na análise qualitativa feita a partir das entrevistas com os alunos, notamos que os estudantes apresentam percepções que sugerem que o professor possui alto conhecimento relativo a alguns aspectos do ensino. Tais percepções foram obtidas a partir de falas que descrevem não apenas opiniões, mas ações durante a aula: o professor consegue tirar dúvidas; leva materiais auxiliares; demonstra ter planejado a aula; promove a participação; apresenta-se próximo ao aluno, propõe avaliações de caráter formativo. Houve também aspectos subjetivos que poderiam ser alvo de incertezas como o fato de os alunos apresentarem interpretações equivocadas a respeito de práticas desenvolvidas extraclasse como o planejamento do curso, ou o conhecimento que o professor tem do currículo.

A tabela 1 ilustra os aspectos que puderam ser reconhecidos a partir das percepções dos estudantes e os aspectos que se apresentaram inconclusivos.

Tabela 1. Percepções dos alunos sobre os conhecimentos do professor.

\begin{tabular}{|l|l|}
\hline \multicolumn{1}{|c|}{ Aspectos reconhecidos } & \multicolumn{1}{c|}{ Aspectos não reconhecidos } \\
\hline Conhecimento do conteúdo & Objetivos educacionais \\
\hline Conhecimento das estratégias de ensino & Currículo \\
\hline $\begin{array}{l}\text { Conhecimento dos procedimentos de } \\
\text { avaliação }\end{array}$ & \\
\hline
\end{tabular}

A análise quantitativa do QA apresenta-se sintetizada na tabela 2. 
Revista Tecné, Episteme y Didaxis: TED. Año 2014, Número Extraordinario. ISSN Impreso: 0121-3814, ISSN web: 2323-0126

Memorias, Sexto Congreso Internacional sobre Formación de Profesores de Ciencias. 08 al 10 de octubre de 2014, Bogotá

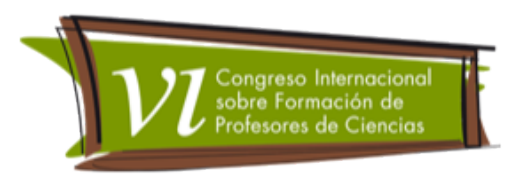

\begin{tabular}{l|l|l|l|l|l}
\hline \hline \multicolumn{1}{c|}{\begin{tabular}{c} 
Tabela 1. Dados obtidos do questionário QA2 para os alunos do período noturno. \\
\hline Categoria
\end{tabular}} & $\begin{array}{c}\text { Itens } \\
\text { respostal de }\end{array}$ & Média & $\begin{array}{c}\text { Desvio Padrão } \\
\text { (SD) }\end{array}$ & $\begin{array}{c}\text { Coeficiente } \\
\text { de Variação } \\
\text { (CV) }\end{array}$ \\
\hline CT & 7 & 161 & 4,71 & 0,52 & 11,0 \\
\hline EIR & 7 & 161 & 4,59 & 0,67 & 14,7 \\
\hline OIC & 7 & 161 & 4,87 & 0,33 & 6,8 \\
\hline CCE & 7 & 161 & 4,35 & 1,13 & 26,1 \\
\hline
\end{tabular}

CT - Conhecimento do Tema; EIR - Estratégias Instrucionais e de Representação; OIC - Objetivos Instrucionais e Contexto; CCE - Conhecimento sobre a Compreensão dos Estudantes

Se analisarmos os dados obtidos de modo a confrontá-los com a análise qualitativa nota-se que as respostas encontram-se entre 4 e 5, o que significa que, segundo os alunos, o professor realiza de forma consistente ações que the conferem um bom conhecimento.

O cálculo do coeficiente de variação (CV) para os itens mostrou homogeneidade nas respostas com exceção do item CCE, o que significa que apesar da média ser acima de 4, há uma maior discordância em relação a esta categoria. Sobre este item, destacamos alguns comentários dos alunos, sendo a maior parte para justificar pontuações baixas:

"Tenta ajudar independente do conhecimento prévio." "Ele avalia o que ele ensina apenas, não pune o aluno por não ter conhecimento prévio e sim tenta ajudar." "A matéria não requer muitos conhecimentos prévios." "Nos exercícios vemos que aparecem nossas dificuldades e me parece que o professor escolhe os exercícios para evidenciar/estimular para superar nossas dificuldades."

Nota-se que apesar de haver um valor elevado para o CV, as justificativas dos alunos têm maior relação com a forma de atuação do professor durante as aulas e com o planejamento das atividades. O conhecimento do conteúdo não é citado diretamente pelos alunos o que torna necessário a análise conjunta com as observações feitas pelo pesquisador. 
Revista Tecné, Episteme y Didaxis: TED. Año 2014, Número Extraordinario. ISSN Impreso: 0121-3814, ISSN web: 2323-0126

Memorias, Sexto Congreso Internacional sobre Formación de Profesores de Ciencias. 08 al 10 de octubre de 2014, Bogotá

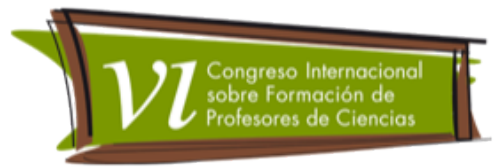

\section{Conclusões}

No desenvolvimento da pesquisa, buscamos o reconhecimento do PCK do professor a partir de uma análise realizada pelo pesquisador frente à análise das percepções dos estudantes. A partir do preceito que o conhecimento profissional se desenvolve na prática e nesta situação há diferentes relações no âmbito educacional, dentre elas a relação professor-aluno, ao estudar os sujeitos envolvidos acreditamos poder ter indícios do conhecimento que se desenvolve.

Assim, ao olharmos para a análise feita pelo pesquisador, notamos que o professor demonstra possuir uma série de componentes relacionados ao PCK. Não é possível afirmarmos que o professor possui um maior ou menor conhecimento de cada componente individualmente e nem é este o objetivo, visto que um profissional com um PCK robusto é aquele que consegue mobilizar os componentes de modo a atuar fornecendo uma prática de ensino que agrega subsídios à aprendizagem.

Ao realizar a análise das percepções dos estudantes, há indícios de que algumas categorias de conhecimento são reconhecidas pelos alunos mais claramente e outras apresentam ideias subjetivas ou interpretações dúbias a respeito do conhecimento que o professor possui.

Notamos que os alunos apresentam percepções que sugerem que o professor possui um alto conhecimento do conteúdo e dos processos de avaliação, e também um bom conhecimento de estratégias metodológicas podendo relacionar às três categorias de conhecimento vinculadas diretamente ao Conhecimento Pedagógico Geral (Modelos e estratégias de ensino, organização e gestão da aula e Comunicação e discurso em sala). Nota-se, porém, que há aspectos subjetivos que poderiam ser alvo de incertezas quanto às conclusões a que chegaram e ainda aspectos que os alunos não conseguem avaliar e que, em geral, referem-se a aspectos que estão além do ambiente de sala de aula. Como exemplo, podemos perceber que poucos estudantes se manifestaram em relação aos objetivos educacionais e em alguns casos surgiram críticas e sugestões de alteração da estrutura do curso em virtude desse fato.

Em relação à análise quantitativa realizada, é possível interpretar que existem indícios sobre alguns aspectos da prática e do conhecimento do professor. Entretanto que a interpretação isolada dos dados numéricos não permite apontar conclusões finais, sendo necessário observar tais dados em conjunto com a análise realizada pelo pesquisador. 
Revista Tecné, Episteme y Didaxis: TED. Año 2014, Número Extraordinario. ISSN Impreso: 0121-3814, ISSN web: 2323-0126

Memorias, Sexto Congreso Internacional sobre Formación de Profesores de Ciencias. 08 al 10 de octubre de 2014, Bogotá

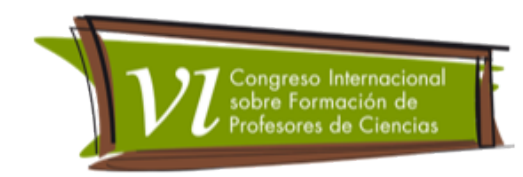

Julgamos que o reconhecimento dos conhecimentos da prática profissional deve ocorrer a partir da observação da mesma e deste modo, como a análise das percepções dos estudantes é também uma análise da prática profissional, esta pode contribuir para melhor compreendermos os conhecimentos ali presentes. Assim, as percepções dos estudantes fornecem informações relevantes para 0 reconhecimento do PCK de professores principalmente quanto utilizadas em conjunto com a observação dos pesquisadores.

\section{Referências Bibliográficas}

Jang, S. J. (2010). Assessing college students' perceptions of a case teacher's pedagogical content knowledge using a newly developed instrument. High Education, 61, $663-678$.

Loughran, J., Mulhall, P., \& Berry, A. (2003). In search of Pedagogical Content Knowledge in Science: Developing ways of Articulating and Documenting Professional Practice. Journal of Research in Science Teaching. 41(4), 370391.

Morine-dershimer, G. \& Kent, T. (1999). The complex nature and sources of teachers' pedagogical knowledge. In J. Gess-newsome; N. G. Lederman (Eds.) examining pedagogical content knowledge: the construct and its implications for science teaching Dordrecht, The Netherlands: Kluwer Academic Publishers, 21-50.

Mortimer, E., F., \& Scott, P. (2002). Atividade discursiva nas salas de aula de ciências: uma ferramenta Sociocultural para analisar e planejar o ensino. Investigações em Ensino de Ciências, 7(3), 283-306.

Nilsson, P., \& van Driel, J. (2010). Teaching together and learning together e Primary science student teacher's and their mentor's joint teaching and learning in the primary classroom. Teaching and Teacher Education, 26, 1309 $-1318$.

Olszewski, J., Neumann, K., \& Fischer, H. E. (2010). Measuring physics teacher's declarative and Procedural PCK. In: TA AR M. F \& ÇAKMAKCl, G. (Ed.), Contemporary science education research: teaching, Ankara, Turkey: Pegem Akademi. 87-94. 
Revista Tecné, Episteme y Didaxis: TED. Año 2014, Número

Extraordinario. ISSN Impreso: 0121-3814, ISSN web: 2323-0126

Memorias, Sexto Congreso Internacional sobre Formación de Profesores de Ciencias. 08 al 10 de octubre de 2014, Bogotá

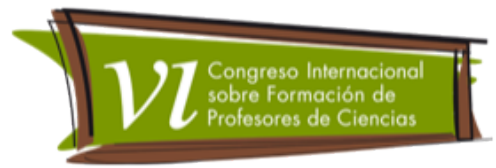

Rollnick, M., Bennett, J., Rhemtula, M., Dharsey, N. \& Ndlovu, T. (2008). The place of subject matter knowledge in pedagogical content knowledge: A case study of South African teachers teaching the amount of substance and chemical equilibrium. International Journal of Science Education, 30 (10), 1365-1387.

Shulman, L. (1987). Knowledge and teaching: Foundations of the new reform. Harvard Educational Review, 57(1), 1-22.

Talanquer, V. (2004). Formación Docente: que conocimiento distingue a los Buenos maestros de química. Educación Química, México, 15(1), 2004.

Tardif, M. (2010). Saberes docentes e formação profissional. 13. ed. Petrópolis: Vozes. 